\title{
Acceptability of HPV Vaccine Among a National Sample of Gay and Bisexual Men
}

\author{
Paul L. Reiter, PHD ${ }^{*}$, , Noel T. Brewer, PHD $^{\star}, \dagger$, Annie-Laurie McRee, MPH${ }^{*}$, Paul Gilbert, \\ MSPH $^{\star}$, and Jennifer S. Smith, PHD ${ }^{*}, \dagger$ \\ *UNC Gillings School of Global Public Health, Chapel Hill, NC \\ †Lineberger Comprehensive Cancer Center, Chapel Hill, NC
}

\begin{abstract}
Objective-Due to higher rates of human papillomavirus (HPV) infection and anal cancer among gay and bisexual men, we aimed to characterize their willingness to get HPV vaccine and identify correlates of vaccine acceptability.

Methods-We surveyed a national sample of men aged 18 to 59 who self-identified as either gay $(\mathrm{n}=236)$ or bisexual $(\mathrm{n}=70)$ during January 2009 . We analyzed data using multivariate logistic regression.
\end{abstract}

Results-Most men had heard of HPV vaccine $(73 \%, 224 / 306)$ and were willing to get it $(74 \%$, 225/306). HPV vaccine acceptability was higher among men who believed their doctor would recommend getting the vaccine ( $\mathrm{OR}=12.87,95 \% \mathrm{CI}: 4.63-35.79)$ and those who were unsure $(\mathrm{OR}=3.15,95 \% \mathrm{CI}: 1.47-6.76)$, as compared to men who believed their doctor would not recommend it. Acceptability was also higher among men who reported 5 or more lifetime sexual partners $(\mathrm{OR}=3.39,95 \%$ CI: $1.34-8.55)$, perceived greater severity of HPV-related disease $(\mathrm{OR}=$ 1.92, 95\% CI: $1.18-3.14)$, perceived higher levels of HPV vaccine effectiveness (OR $=1.97,95 \%$ CI: 1.27-3.06), or reported higher levels of anticipated regret if they did not get vaccinated and later developed an HPV infection (OR $=2.39,95 \%$ CI: $1.57-3.61)$.

Conclusions-HPV vaccine acceptability was high among gay and bisexual men. These findings identify potentially important beliefs and attitudes for future communication efforts about HPV and HPV vaccine among gay and bisexual men.

Human papillomavirus (HPV) infection is widespread among males, with recent prevalence estimates ranging up to $73 \% \cdot{ }^{1-4} \mathrm{HPV}$-infected men face potentially severe health consequences, although most infections resolve spontaneously. An estimated 63\% of oropharyngeal cancers, $93 \%$ of anal cancers, and 36\% of penile cancers in the United States (US) are attributable to infection with oncogenic HPV types (mainly types 16 and 18). ${ }^{5}$ Nononcogenic HPV types (types 6 and 11) cause anogenital warts. ${ }^{6}$

Copyright $\odot 2010$ American Sexually Transmitted Diseases Association All rights reserved.

Correspondence: Paul L. Reiter, PhD, Department of Health Behavior and Health Education, University of North Carolina Gillings School of Global Public Health, 323D Rosenau Hall, CB 7440, Chapel Hill, NC 27599-7440. preiter@email.unc.edu.. 
HPV-related disease is of particular concern for gay and bisexual men. The estimated prevalence of anal HPV infection among gay and bisexual men is about $60 \%$ among human immunodeficiency virus (HIV)-negative individuals and even higher among HIV-positive individuals, perhaps over $90 \% .^{7-9}$ Men who have sex with men (MSM) are also at greater risk for anal cancer compared with the general population, ${ }^{10-12}$ with incidence rates increasing over the last few decades. ${ }^{13}$

While a quadrivalent HPV vaccine is currently approved for use in females aged 9 to 26 years in the United States, ${ }^{14}$ studies have also shown the vaccine to be efficacious in males. Early results have shown reductions in persistent HPV infection and genital warts among vaccinated young men, including MSM. ${ }^{15-17}$ Although some men may not derive full benefit due to previous exposure to HPV types in the vaccine, it may offer them important protection against HPV vaccine types they have not been exposed to. As with females, HPV vaccination likely offers the greatest benefit to males if administered before sexual debut. ${ }^{18,19}$ Several countries have licensed HPV vaccine for use in males, though the United States is not currently one of them. ${ }^{20}$ Austria is the only country to currently recommend HPV vaccination for young males. ${ }^{20}$

In the event of approval of prophylactic HPV vaccine for use among males in the United States, it is important to examine vaccine acceptability and potential correlates such as knowledge and beliefs. Most studies that have addressed these topics in men have included no or very few gay and bisexual men. ${ }^{21-26}$ The limited research conducted among gay and bisexual men (primarily using convenience samples recruited at community events or sexual health centers) found low levels of awareness and knowledge about HPV, ${ }^{27,28}$ as well as moderate interest in receiving the vaccine. ${ }^{29}$

In this report, we aimed to characterize correlates of acceptability among a national sample of gay and bisexual men. We examine modifiable beliefs as potential correlates of HPV vaccine acceptability among this high-risk population, focusing on constructs from health behavior theory and previous research on HPV vaccine among adult women, parents, and adolescent females. ${ }^{30-32}$

\section{MATERIALS AND METHODS}

\section{Study Design}

We interviewed men aged 18 to 59 years who were members of an existing national panel of US households maintained by Knowledge Networks (Menlo Park, CA) in January 2009, oversampling men who self-identified as gay or bisexual for our study. Knowledge Networks identified prospective panel members using list-assisted, random-digit dialing. Households containing one or more panel members receive free internet access in exchange for panel members completing multiple internet-based surveys each month. Panel members in households with existing computer and internet access accumulate points as they complete surveys, which can then be redeemed for small cash payments at regular intervals. Of 874 men invited to participate, 609 (70\%) completed our cross-sectional, online survey. ${ }^{33}$ We report data collected from men who self-identified as either gay $(n=236)$ or bisexual $(n=70)$, excluding 12 men who indicated that they were not heterosexual but did 
not label their sexual orientation as either gay or bisexual. The Institutional Review Board at the University of North Carolina approved the study.

\section{Measures}

The University of North Carolina Men's Health Survey is available online at http:// www.unc.edu/ ntbrewer/hpv.htm. We developed survey items based on our previous HPV vaccine research involving females, parents, and healthcare providers. ${ }^{31,32,34} \mathrm{We}$ cognitively tested the survey with 28 gay and bisexual men and further refined it with 8 additional men (including 5 gay and bisexual men) before the study.

The survey measured HPV vaccine acceptability using 5 items assessing how willing a participant would be to get HPV vaccine if it were approved for use in males $(\alpha=0.97)$. Response options were "definitely not willing," "probably not willing," "not sure," "probably willing," and "definitely willing." We classified each participant as either "willing to get HPV vaccine" (responded probably or definitely willing to 3 or more items) or "not willing to get HPV vaccine."

The survey measured HPV awareness by asking participants if they had ever heard of HPV before the survey. We calculated an HPV knowledge score by summing correct responses to 9 individual items (each correct answer was 1 point) asked only of men who had heard of HPV (Fig. 1). For analyses, we classified participants as "unaware of HPV" if they had never heard of HPV, aware of HPV with "low knowledge" if they had heard of HPV but answered 4 or less knowledge items correctly, or aware of HPV with "high knowledge" if they had heard of HPV and answered at least 5 knowledge items correctly.

After providing informative statements about HPV and HPV vaccine, the survey assessed awareness of the vaccine by asking participants if they had ever heard of it before the survey. The statements informed participants that HPV is a common sexually transmitted infection (STI), about diseases associated with HPV, and that a vaccine exists to protect girls and young women against cervical disease. Participants indicated whether they had ever received any doses of HPV vaccine, attempted to get HPV vaccine but were unsuccessful, talked to a doctor about getting HPV vaccine for themselves, whether any family members or friends had received HPV vaccine, and where they would most likely go to get HPV vaccine (if it were approved for males). The survey also assessed whether participants thought their healthcare providers would recommend they get the vaccine if it were approved for males.

The survey used multi-item scales to measure perceived knowledge of HPV-related disease ( 3 items, possible range $=1-4, a=0.74$ ), level of concern about getting HPV-related disease ( 3 items, possible range $=1-4, a=0.53$ ), perceived severity of HPV-related disease ( 3 items, possible range $=1-4, a=0.69$ ), and anticipated regret of not getting HPV vaccine and later developing genital warts or an HPV infection that could lead to cancer ( 2 items, possible range $=1-4, a=0.88)$. HPV-related diseases addressed in the perceived knowledge, concern, and perceived severity scales were genital warts, anal cancer, and oral cancer. Perceived knowledge response options ranged from "nothing at all" to "quite a lot," 
while concern, perceived severity, and anticipated regret items had response options ranging from "not at all" to "quite a lot."

The survey measured perceived potential barriers to obtaining HPV vaccine with a 4-item scale (possible range $=1-5, a=0.65$ ) that addressed adverse effects of HPV vaccination, cost of HPV vaccine, and difficulty in finding a health care provider with the vaccine available for males (if approved for use). For each perceived potential barrier, response options ranged from "not at all" to "extremely." The survey also assessed perceived effectiveness of the vaccine against HPV-related disease (4 items, possible range $=1-5, a=$ 0.94 ) and perceived likelihood of getting HPV-related disease (4 items, possible range $=1-$ $5, a=0.85$ ) using multi-item scales. HPV-related diseases addressed in these scales were genital warts, anal cancer, oral cancer, and penile cancer. Response options ranged from "no protection" to "complete protection" for effectiveness items and "no chance" to "certain I will get (HPV-related disease)" for likelihood items.

Participants provided information on demographic variables and health behaviors (Table 1). We defined "urban" as living in a metropolitan statistical area and "rural" as living outside of an metropolitan statistical area. ${ }^{35}$ The survey also collected information on reported history of STIs and cancer (oral, anal, or penile) or lesions (anal or penile).

\section{Data Analysis}

We used logistic regression models to examine bivariate correlates of HPV vaccine acceptability. Statistically significant bivariate predictors $(P<0.05)$ were entered into a multivariate logistic regression model. We analyzed unweighted data using SPSS version 16.0 (SPSS Inc., Chicago, IL). All statistical tests were 2-tailed, using a critical a of 0.05.

\section{RESULTS}

\section{Participant Characteristics}

Most participants were non-Hispanic white (81\%), less than 50 years old (60\%), reported an income of at least $\$ 60,000(60 \%)$, employed (80\%), had health insurance (86\%), and lived in an urban area (93\%) (Table 1). A majority of participants were nonsmokers (72\%) and had either not received or were unsure if they had received one or more doses of hepatitis B vaccine (56\%). Most men reported that they had not initiated sex before age $16(65 \%)$ and a history of 5 or more sexual partners during their lifetime (89\%) (median number of reported lifetime sexual partners $=25$ ). Seventeen percent of men reported a history of HIV infection, $32 \%$ reported a history of other STIs, and 2\% indicated a history of cancer (oral, anal, or penile) or lesions (anal or penile).

\section{HPV and HPV Vaccine Awareness and Knowledge}

Most men (79\%) reported hearing of HPV before the survey, but knowledge levels about HPV tended to be low among those who had. Men, on average, answered 49\% of the 9 knowledge questions correctly (mean $=4.39$, median $=4$ of 9 items correct). Most participants knew that HPV is an STI (74\%) and that it is a common infection (74\%) (Fig. 1). Only 58\% thought HPV causes health problems for males, with even fewer knowing 
HPV can cause genital warts $(46 \%)$ and cancer (anal cancer $=32 \%$, penile cancer $=28 \%$, oral cancer $=25 \%$ ). Knowledge items with the highest percentage of incorrect responses concerned whether HPV causes genital herpes (33\%), oral cancer (25\%), or penile cancer (24\%). In terms of HPV vaccine, most men (73\%) reported hearing of it before the survey.

\section{Beliefs About HPV and HPV Vaccine}

Men expressed relatively low levels of perceived knowledge about HPV-related disease (mean $=1.80, \mathrm{SD}=0.63$ ) and concern about getting HPV-related disease (mean $=1.55, \mathrm{SD}$ $=0.54$ ), as well as moderate levels of perceived likelihood of getting HPV-related disease (mean $=2.19, \mathrm{SD}=0.55$ ). Participants generally perceived HPV-related disease to be severe (mean $=3.32, \mathrm{SD}=0.66$ ). Participants also perceived HPV vaccine to be moderately effective in protecting against HPV-related disease (mean $=3.03, \mathrm{SD}=0.82$ ), some barriers to getting HPV vaccine if it were available for males (mean $=2.67, \mathrm{SD}=0.85$ ), and high levels of anticipated regret if they did not get vaccinated and later got an HPV infection (mean $=3.39, \mathrm{SD}=0.84)$. While about one-third of men $(34 \%)$ thought their doctor would recommend they get HPV vaccine if it were approved for males, almost half were unsure $(48 \%)$.

\section{HPV Vaccine Uptake and Acceptability}

No men had received HPV vaccine, 3\% reported talking to a doctor previously about getting the vaccine for themselves, and $8 \%$ reported a family member or friend had been vaccinated. Three men reported trying to get HPV vaccine but were unsuccessful in doing so, indicating that affordability of the vaccine $(\mathrm{n}=2)$ and the doctor not giving HPV vaccine to males $(\mathrm{n}=$ 1) prevented them from getting it. If approved for males, men indicated they would most likely go to a primary healthcare provider's office $(78 \%)$ or gay health center $(8 \%)$ to get HPV vaccine.

Approximately 74\% (225/306) of men were willing to receive HPV vaccine. Multiple variables were associated with acceptability of HPV vaccine in bivariate analyses (Tables 1 and 2). Men who either thought or were unsure if their doctor would recommend HPV vaccine, had received one or more doses of hepatitis B vaccine, or reported 5 or more lifetime sexual partners were more willing to get HPV vaccine (all $P<0.05$ ). Furthermore, men willing to get vaccinated reported higher levels of concern about getting HPV-related disease, perceived severity of HPV-related disease, perceived likelihood of getting HPVrelated disease, perceived effectiveness of HPV vaccine, and anticipated regret if they did not get vaccinated and later became infected with HPV (all $P<0.05$ ).

In multivariate analysis (Table 3), acceptability was higher among men if they either thought $(\mathrm{OR}=12.87,95 \%$ CI: $4.63-35.79)$ or were unsure $(\mathrm{OR}=3.15,95 \%$ CI: $1.47-6.76)$ if their doctor would recommend they get HPV vaccine compared with those who thought their doctor would not recommend the vaccine, if made available for males. Acceptability was also higher among those who had 5 or more lifetime sexual partners $(\mathrm{OR}=3.39,95 \% \mathrm{CI}$ : 1.34-8.55), perceived HPV-related disease to be more severe (OR $=1.92,95 \%$ CI: 1.18 3.14), perceived HPV vaccine to be more effective ( $\mathrm{OR}=1.97,95 \%$ CI: $1.27-3.06)$, or 
reported greater anticipated regret if they did not get vaccinated and an HPV infection later developed $(\mathrm{OR}=2.39,95 \%$ CI: $1.57-3.61)$.

\section{DISCUSSION}

If approved for use in males, HPV vaccine may offer great benefits to gay and bisexual men due to their high rates of HPV infection ${ }^{7-9}$ and HPV-associated anal cancer. ${ }^{12}$ We currently know little about the acceptability of the vaccine among gay and bisexual men. In this national sample of gay and bisexual men, most were willing to get HPV vaccine.

Furthermore, many of the identified correlates of HPV vaccine acceptability are modifiable and offer potential targets for future research addressing HPV and HPV vaccine in gay and bisexual males.

About three-fourth of participants were willing to get vaccinated against HPV. This level of HPV vaccine acceptability is higher than a past study conducted among MSM. ${ }^{29}$

Acceptability of HPV vaccine was higher among men who perceived HPV-related disease to be more severe, perceived HPV vaccine to be more effective, or thought or were unsure if their doctor would recommend they get HPV vaccine (although effect estimates for doctor's recommendation were imprecise due to small cell counts and should be interpreted accordingly). These findings are similar to those of HPV vaccine acceptability research conducted among females and parents of adolescent girls (before federal approval of the vaccine for females). ${ }^{30}$ While males have also reported increased willingness to get HPV vaccine if their doctor recommended it, ${ }^{22}$ neither perceived severity of HPV-related disease nor perceived HPV vaccine effectiveness were multivariate correlates of HPV vaccine acceptability in a previous study among heterosexual males. ${ }^{23}$ Acceptability was also higher among men in our study who reported greater anticipated regret if they did not get vaccinated and an HPV infection later developed. While we identified anticipated regret as a key predictor of HPV vaccine uptake among adolescent females, ${ }^{36}$ it has not been previously examined as a correlate of HPV vaccine acceptability among males, to our knowledge. These findings identify potentially important beliefs and attitudes for future communication efforts about HPV and HPV vaccine among gay and bisexual men.

Although most participants were willing to get vaccinated, knowledge of potential health consequences of HPV infection was low. Furthermore, over 20\% of men had not even heard of HPV before the survey. These findings are in line with previous reports of low HPV knowledge among gay and bisexual men. ${ }^{27,28}$ Given the high levels of anal HPV infection among gay and bisexual men, ${ }^{7-9}$ these results are especially concerning. Future efforts need to ensure that gay and bisexual men are aware of not only HPV and how it is transmitted, but also diseases associated with HPV infection and how infected men can reduce their risk of developing HPV-related cancers. Such efforts may increase informed decision-making about HPV vaccine (and potentially vaccine acceptability) among this high-risk population.

A few important issues will need to be considered before targeting gay and bisexual men for vaccination should the vaccine become available for males. HPV vaccination likely offers the greatest benefit if administered before sexual debut. ${ }^{18,19}$ However, most MSM report engaging in their first same-sex experience before disclosing their sexual orientation to 
others. ${ }^{37}$ Consequently, men identifying as gay and bisexual who have not yet had sexual intercourse (the ideal target population) may be a difficult population to identify. One alternative public health strategy may be to target all males at an early age before sexual intercourse, similar to the current strategy for vaccinating females.

Many sexually active gay and bisexual men will likely seek HPV vaccine if it becomes available for males, including those with previous HPV infections. In our study, as well as others among primarily heterosexual men, ${ }^{22,25}$ acceptability of HPV vaccine was higher among men with more lifetime sexual partners, a marker of risk for HPV infection. Nonetheless, most MSM are not currently infected in the anal canal with either HPV 16 or 18 and are unlikely to be infected with all 4 HPV types the quadrivalent vaccine protects against. ${ }^{8,9}$ If additional research determines that vaccinating sexually active men offers health benefits, these gay and bisexual men with previous sexual activity may become an important population for ensuring HPV vaccination.

The strengths of our study include the use of a national sample, a high participation rate, and examining a wide range of possible correlates of willingness to get HPV vaccine. We also focused on gay and bisexual men, who are at high risk for HPV-related disease. Limitations include the study occurring before HPV vaccine licensure for males in the United States and the inclusion of men outside the age range of those in clinical trials involving HPV vaccine safety and efficacy in males. ${ }^{15-17}$ Age, however, was not associated with vaccine acceptability. While we used members of an online survey panel, the panel has been shown to closely match the US population on many demographic features. ${ }^{38,39}$ The main outcome, willingness to get HPV vaccine, may overstate behavior that we would observe if HPV vaccine is approved for use in males since intent does not always translate into health behavior. ${ }^{40,41}$ This issue may be especially relevant in the case of HPV vaccination in the United States since the vaccine is not currently provided free of charge within schools, as in other countries. ${ }^{42}$

The findings of the current study suggest that a substantial proportion of gay and bisexual men are willing to get HPV vaccine. Modifiable beliefs, including perceived HPV vaccine effectiveness and anticipated regret, may be important to future communication efforts about HPV and HPV vaccine among gay and bisexual men. While future research involving males in the likely targeted age range for HPV vaccine is warranted, our results offer early insight into both HPV vaccine acceptability among gay and bisexual men and correlates of this acceptability.

\section{Acknowledgments}

Supported by grants from the American Cancer Society (MSRG-06-259-01-CPPB), the National Cancer Institute (R25 CA57726), and the Investigator-Initiated Studies Program of Merck and Co., Inc. A research grant to N.T.B. from Merck and Co., Inc. funded the study. J.S.S. has received research grants, honoraria and consulting fees during the last 4 years from GlaxoSmithKline (GSK) and worked collaboratively on a research grant from Merck and Co., Inc. Corporation.

The opinions expressed in this paper are those of the authors and do not necessarily represent those of Merck and Co., Inc. Merck and Co., Inc. played no role in the study design, planning, implementation, analysis, or reporting of the findings. 


\section{REFERENCES}

1. Dunne EF, Nielson CM, Stone KM, et al. Prevalence of HPV infection among men: A systematic review of the literature. J Infect Dis. 2006; 194:1044-1057. [PubMed: 16991079]

2. Nielson CM, Harris RB, Dunne EF, et al. Risk factors for anogenital human papillomavirus infection in men. J Infect Dis. 2007; 196:1137-1145. [PubMed: 17955431]

3. Nyitray A, Nielson CM, Harris RB, et al. Prevalence of and risk factors for anal human papillomavirus infection in heterosexual men. J Infect Dis. 2008; 197:1676-1684. [PubMed: 18426367]

4. Giuliano AR, Lazcano-Ponce E, Villa LL, et al. The human papillomavirus infection in men study: Human papillomavirus prevalence and type distribution among men residing in Brazil, Mexico, and the United States. Cancer Epidemiol Biomarkers Prev. 2008; 17:2036-2043. [PubMed: 18708396]

5. Gillison ML, Chaturvedi AK, Lowy DR. HPV prophylactic vaccines and the potential prevention of noncervical cancers in both men and women. Cancer. 2008; 113(suppl 10):3036-3046. [PubMed: 18980286]

6. Greer CE, Wheeler CM, Ladner MB, et al. Human papillomavirus (HPV) type distribution and serological response to HPV type 6 virus-like particles in patients with genital warts. J Clin Microbiol. 1995; 33:2058-2063. [PubMed: 7559948]

7. van der Snoek EM, Niesters HG, van Doornum GJ, et al. Acquisition and clearance of perianal human papillomavirus infection in relation to HIV-positivity in men who have sex with men in the Netherlands. Acta Derm Venereol. 2005; 85:437-443. [PubMed: 16159738]

8. Chin-Hong PV, Vittinghoff E, Cranston RD, et al. Age-specific prevalence of anal human papillomavirus infection in HIV-negative sexually active men who have sex with men: The EXPLORE study. J Infect Dis. 2004; 190:2070-2076. [PubMed: 15551204]

9. Palefsky JM, Holly EA, Ralston ML, et al. Prevalence and risk factors for human papillomavirus infection of the anal canal in human immunodeficiency virus (HIV)-positive and HIV-negative homosexual men. J Infect Dis. 1998; 177:361-367. [PubMed: 9466522]

10. Daling JR, Weiss NS, Hislop TG, et al. Sexual practices, sexually transmitted diseases, and the incidence of anal cancer. N Engl J Med. 1987; 317:973-977. [PubMed: 2821396]

11. Holly EA, Whittemore AS, Aston DA, et al. Anal cancer incidence: Genital warts, anal fissure or fistula, hemorrhoids, and smoking. J Natl Cancer Inst. 1989; 81:1726-1731. [PubMed: 2810388]

12. Palefsky JM, Rubin M. The epidemiology of anal human papillomavirus and related neoplasia. Obstet Gynecol North Am. 2009; 36:187-200.

13. Cress RD, Holly EA. Incidence of anal cancer in California: Increased incidence among men in San Francisco, 1973-1999. Prev Med. 2003; 36:555-560. [PubMed: 12689800]

14. Food and Drug Administration. Product approval information-licensing action (package insert). Gardasil (quadrivalent human papillomavirus types 6, 11, 16, 18). Merck and Co.; Whitehouse Station, NJ: Available at: http://www.fda.gov/cber/label/HPVmer060806LB.pdf

15. Giuliano, A.; Palefsky, J.; Male Quadrivalent HPV Vaccine Efficacy Trial Study Group. The efficacy of quadrivalent HPV (types 6/11/16/18) vaccine in reducing the incidence of HPV infection and HPV-related genital disease in young men; Paper presented at: European Research Organization on Genital Infection and Neoplasia (EUROGIN) International Multidisciplinary Conference; Nice, France. 2008; Nov. Available at: http://www.eurogin.com

16. Palefsky, J.; Giuliano, A. Quadrivalent HPV vaccine efficacy in men having sex with men. Paper presented at: International Papillomavirus Conference; Malmo, Sweden. 2009; May.

17. Palefsky, J.; Giuliano, A.; Male Quadrivalent HPV Vaccine Efficacy Trial Study Group. Efficacy of the quadrivalent HPV vaccine against HPV 6/11/16/18-related genital infection in young men; Paper presented at: European Research Organization on Genital Infection and Neoplasia (EUROGIN) International Multidisciplinary Conference; Nice, France. Nov. 2008 Available at: http://www.eurogin.com

18. Markowitz LE, Dunne EF, Saraiya M, et al. Quadrivalent human papillomavirus vaccine: Recommendations of the Advisory Committee on Immunization Practices (ACIP). MMWR Recomm Rep. 2007; 56:1-24. [PubMed: 17380109] 
19. Hildesheim A, Herrero R. Human papillomavirus vaccine should be given before sexual debut for maximum benefit. J Infect Dis. 2007; 196:1431-1432. [PubMed: 18008218]

20. Koulova A, Tsui J, Irwin K, et al. Country recommendations on the inclusion of HPV vaccines in national immunization programmes among high-income countries, June 2006-January 2008. Vaccine. 2008; 26:6529-6541. [PubMed: 18805453]

21. Ferris DG, Waller JL, Miller J, et al. Men's attitudes toward receiving the human papillomavirus vaccine. J Low Genit Tract Dis. 2008; 12:276-281. [PubMed: 18820541]

22. Ferris DG, Waller JL, Miller J, et al. Variables associated with human papillomavirus (HPV) vaccine acceptance by men. J Am Board Fam Med. 2009; 22:34-42. [PubMed: 19124631]

23. Gerend MA, Barley J. Human papillomavirus vaccine acceptability among young adult men. Sex Transm Dis. 2009; 36:58-62. [PubMed: 18830138]

24. Gerend MA, Magloire ZF. Awareness, knowledge, and beliefs about human papillomavirus in a racially diverse sample of young adults. J Adolesc Health. 2008; 42:237-242. [PubMed: 18295131]

25. Jones M, Cook R. Intent to receive an HPV vaccine among university men and women and implications for vaccine administration. J Am Coll Health. 2008; 57:23-32. [PubMed: 18682342]

26. Lenselink CH, Schmeink CE, Melchers WJ, et al. Young adults and acceptance of the human papillomavirus vaccine. Public Health. 2008; 122:1295-1301. [PubMed: 18619631]

27. Pitts MK, Fox C, Willis J, et al. What do gay men know about human papillomavirus? Australian gay men's knowledge and experience of anal cancer screening and human papillomavirus. Sex Transm Dis. 2007; 34:170-173. [PubMed: 16837830]

28. Tider DS, Parsons JT, Bimbi DS. Knowledge of human papillomavirus and effects on sexual behavior of gay/bisexual men: a brief report. Int J STD AIDS. 2005; 16:707-708. [PubMed: 16212721]

29. Simatherai D, Bradshaw CS, Fairley CK, et al. What men who have sex with men think about the human papillomavirus vaccine. Sex Transm Infect. 2009; 85:148-149. [PubMed: 19153110]

30. Brewer NT, Fazekas KI. Predictors of HPV vaccine acceptability: A theory-informed, systematic review. Prev Med. 2007; 45:107-114. [PubMed: 17628649]

31. Fazekas KI, Brewer NT, Smith JS. HPV vaccine acceptability in a rural Southern area. J Womens Health. 2008; 17:539-548.

32. Reiter PL, Brewer NT, Gottlieb SL, et al. Parents' health beliefs and HPV vaccination of their adolescent daughters. Soc Sci Med. 2009; 69:475-480. [PubMed: 19540642]

33. Gilbert P, Brewer NT, Reiter PL, et al. HPV vaccine acceptability in heterosexual, gay, and bisexual men. Working paper.

34. Keating KM, Brewer NT, Gottlieb SL, et al. Potential barriers to HPV vaccine provision among medical practices in an area with high rates of cervical cancer. J Adolesc Health. 2008; 43(suppl 4):S61-S67. [PubMed: 18809147]

35. Office of Management and Budget. Standards for defining metropolitan and micropolitan statistical areas; notice. Federal Register. Dec 27; 2000 65(249):82227-82238. Available at: http:// www.whitehouse.gov/omb/fedreg/metroareas122700.pdf.

36. Brewer NT, Gottlieb SL, Reiter PL, et al. Longitudinal predictors of HPV vaccine uptake. Working paper.

37. Schindhelm RK, Hospers HJ. Sex with men before coming-out: Relation to sexual activity and sexual risk-taking behavior. Arch Sex Behav. 2004; 33:585-591. [PubMed: 15483372]

38. Baker, LC.; Bundorf, MK.; Singer, S., et al. Validity of the survey of health and internet and knowledge network's panel and sampling. 2003. UpdatedAvailable at: http://www.cdc.gov/pcd/ issues/2004/oct/pdf/04_0004_01.pdf

39. Dennis, JM. Description of within-panel survey sampling methodology: the knowledge networks approach. 2009. UpdatedAvailable at: http://www.knowlegenetworks.com/ganp/docs/KN \%20Within-Panel\%20Survey20Sampling\%20Methodology.pdf

40. Johnston KL, White KM. Binge-drinking: A test of the role of group norms in the theory of planned behaviour. Psychol Health. 2003; 18:63-77. 
41. Rivis A, Sheeran P. Social influences and the theory of planned behaviour: Evidence for a direct relationship between prototypes and young people's exercise behaviour. Psychol Health. 2003; 18:567-583.

42. Shefer A, Markowitz L, Deeks S, et al. Early experience with human papillomavirus vaccine introduction in the United States, Canada and Australia. Vaccine. 2008; 26(suppl 10):K68-K75. [PubMed: 18847559] 


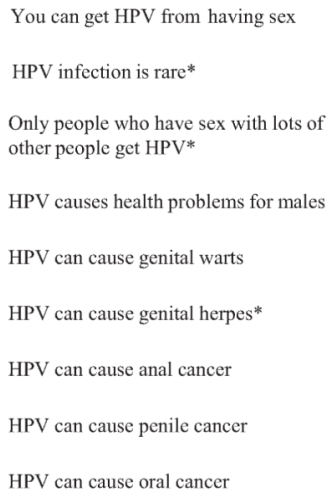

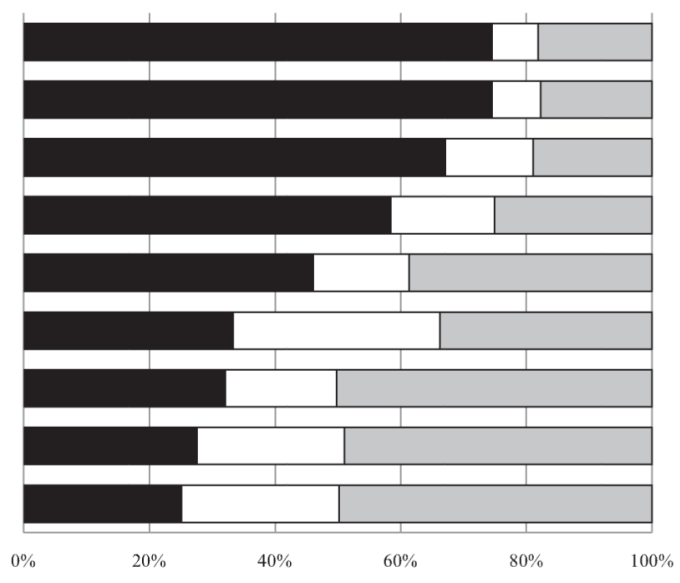

- Correct $\square$ Incorrect aDon't Know

Figure 1.

Responses to HPV knowledge items among gay and bisexual men who had heard of HPV before survey $(\mathrm{n}=243)$. Correct answer is yes, except for items with superscript $\left(^{*}\right)$. 


\section{TABLE 1}

Categorical Correlates of HPV Vaccine Acceptability Among Gay and Bisexual Men ( $\mathrm{n}=306)$

\begin{tabular}{|c|c|c|}
\hline & $\begin{array}{l}\text { No. Willing to Get HPV Vaccine/ } \\
\text { Total No. in Category (n \%) }\end{array}$ & $\begin{array}{c}\text { Bivariate } \\
\text { OR }(95 \% \text { CI })\end{array}$ \\
\hline \multicolumn{3}{|l|}{ Demographic characteristics } \\
\hline \multicolumn{3}{|l|}{ Sexual self-identity } \\
\hline Bisexual & $48 / 70(69)$ & ref. \\
\hline Gay & $177 / 236(75)$ & $1.38(0.77-2.47)$ \\
\hline \multicolumn{3}{|l|}{ Age (yr) } \\
\hline $18-39$ & $41 / 59(69)$ & ref. \\
\hline $40-49$ & $96 / 124(77)$ & $1.51(0.75-3.02)$ \\
\hline $50-59$ & $88 / 123(71)$ & $1.10(0.56-2.18)$ \\
\hline \multicolumn{3}{|l|}{ Race/ethnicity } \\
\hline White, non-Hispanic & $180 / 247(73)$ & ref. \\
\hline Other race/ethnicity & $45 / 59(76)$ & $1.20(0.62-2.32)$ \\
\hline \multicolumn{3}{|l|}{ Marital status } \\
\hline Divorced, widowed, separated, never married & $117 / 160(73)$ & ref. \\
\hline Living with partner or married & $108 / 146(74)$ & $1.05(0.63-1.74)$ \\
\hline \multicolumn{3}{|l|}{ Education level } \\
\hline No college degree & $94 / 136(69)$ & ref. \\
\hline College degree & $131 / 170(77)$ & $1.50(0.90-2.50)$ \\
\hline \multicolumn{3}{|l|}{ Household income } \\
\hline$<\$ 60,000$ & $87 / 122(71)$ & ref. \\
\hline$\varepsilon \$ 60,000$ & $138 / 184(75)$ & $1.21(0.72-2.02)$ \\
\hline \multicolumn{3}{|l|}{ Employment status } \\
\hline Not currently employed & $40 / 60(67)$ & ref. \\
\hline Currently employed & $185 / 246(75)$ & $1.52(0.82-2.79)$ \\
\hline \multicolumn{3}{|l|}{ Health insurance status } \\
\hline No & $30 / 44(68)$ & ref. \\
\hline Yes & 195/262 (74) & $1.36(0.68-2.71)$ \\
\hline \multicolumn{3}{|l|}{ Urbanicity } \\
\hline Rural & $16 / 20(80)$ & ref. \\
\hline Urban & 209/286 (73) & $0.68(0.22-2.09)$ \\
\hline \multicolumn{3}{|l|}{ HPV and HPV vaccine } \\
\hline \multicolumn{3}{|l|}{ Awareness/knowledge about HPV } \\
\hline Never heard of HPV before survey & $43 / 63(68)$ & $0.70(0.36-1.38)$ \\
\hline Heard of HPV, at or below median knowledge score & $93 / 125(74)$ & $0.95(0.53-1.69)$ \\
\hline Heard of HPV, above median knowledge score & $89 / 118(75)$ & ref. \\
\hline \multicolumn{3}{|l|}{ Heard of HPV vaccine before survey } \\
\hline No & $60 / 82(73)$ & ref. \\
\hline Yes & $165 / 224(74)$ & $1.03(0.58-1.82)$ \\
\hline \multicolumn{3}{|l|}{ Family member or friend has gotten HPV vaccine } \\
\hline No & 208/283 (73) & ref. \\
\hline
\end{tabular}




\begin{tabular}{|c|c|c|}
\hline & $\begin{array}{l}\text { No. Willing to Get HPV Vaccine/ } \\
\text { Total No. in Category (n \%) }\end{array}$ & $\begin{array}{c}\text { Bivariate } \\
\text { OR }(95 \% \mathrm{CI})\end{array}$ \\
\hline Yes & $17 / 23(74)$ & $1.02(0.39-2.69)$ \\
\hline \multicolumn{3}{|c|}{ Think doctor would recommend HPV vaccine } \\
\hline No & $25 / 56(45)$ & ref. \\
\hline Do not know & 105/147 (71) & $3.10(1.64-5.86)^{*}$ \\
\hline Yes & 95/103 (92) & $14.73(6.03-35.98)^{*}$ \\
\hline \multicolumn{3}{|l|}{ Health and health behaviors } \\
\hline \multicolumn{3}{|l|}{ Smoking status } \\
\hline Nonsmoker & $157 / 219(72)$ & ref. \\
\hline Smoker & $68 / 87(78)$ & $1.41(0.79-2.54)$ \\
\hline \multicolumn{3}{|l|}{ Hepatitis B vaccination history } \\
\hline No doses received/do not know & 118/171 (69) & ref. \\
\hline At least one dose received & 107/135 (79) & $1.72(1.01-2.91)^{\dagger}$ \\
\hline \multicolumn{3}{|l|}{ Age at first sexual intercourse (yr) } \\
\hline$<16$ & $83 / 108(77)$ & $1.31(0.76-2.26)$ \\
\hline$\geq 16$ & $142 / 198(72)$ & ref. \\
\hline \multicolumn{3}{|l|}{ No. lifetime sexual partners } \\
\hline$<5$ & $18 / 35(51)$ & ref. \\
\hline 25 & 207/271 (76) & $3.06(1.49-6.27)^{*}$ \\
\hline \multicolumn{3}{|l|}{ HIV status } \\
\hline Negative & $185 / 255(73)$ & ref. \\
\hline Positive & $40 / 51(78)$ & $1.38(0.67-2.83)$ \\
\hline \multicolumn{3}{|l|}{ Other prior STI diagnosis } \\
\hline No & $152 / 209(73)$ & ref. \\
\hline Yes & 73/97 (75) & $1.14(0.66-1.98)$ \\
\hline \multicolumn{3}{|c|}{$\begin{array}{l}\text { Prior diagnosis of cancer (oral, anal, penile) or lesions } \\
\text { (anal, penile) }\end{array}$} \\
\hline No & 222/301 (74) & ref. \\
\hline Yes & $3 / 5(60)$ & $0.53(0.09-3.25)$ \\
\hline
\end{tabular}

HPV indicates human papillomavirus; OR, odds ratio; CI, confidence interval; ref., referent group; HIV, human immunodeficiency virus; STI, sexually transmitted infection.

${ }^{*} P<0.01$.

${ }^{\dagger} P<0.05$. 
TABLE 2

Continuous Correlates of HPV Vaccine Acceptability Among Gay And Bisexual Men ( $n=306)$

\begin{tabular}{lccc}
\hline & \multicolumn{2}{c}{ Mean (SD) } & Bivariate \\
\cline { 2 - 3 } & Not Willing (n= 81) & Willing (n= 225) & OR (95\% CI) \\
\hline Perceived knowledge of HPV-related disease & $1.72(0.63)$ & $1.83(0.62)$ & $1.37(0.89-2.10)$ \\
Concern about getting HPV-related disease & $1.40(0.51)$ & $1.60(0.54)$ & $2.21(1.25-3.91) *$ \\
Perceived severity of HPV-related disease & $3.09(0.76)$ & $3.41(0.60)$ & $1.98(1.36-2.88) *$ \\
Perceived likelihood of getting HPV-related disease & $2.03(0.63)$ & $2.25(0.51)$ & $2.22(1.32-3.72)^{*}$ \\
Perceived barriers to getting HPV vaccine & $2.73(0.88)$ & $2.64(0.83)$ & $0.88(0.65-1.19)$ \\
Perceived effectiveness of HPV vaccine & $2.58(0.87)$ & $3.19(0.74)$ & $2.76(1.91-3.97) *$ \\
$\begin{array}{l}\text { Anticipated regret if chose not to get vaccinated and later } \\
\text { developed HPV infection }\end{array}$ & $2.81(1.05)$ & $3.60(0.62)$ & $3.02(2.17-4.20) *$ \\
\hline
\end{tabular}

HPV indicates human papillomavirus; OR, odds ratio; $\mathrm{CI}$, confidence interval.

${ }^{*} P<0.01$. 
TABLE 3

Multivariate Correlates of HPV Vaccine Acceptability Among Gay and Bisexual Men $(n=306)$

\begin{tabular}{|c|c|}
\hline & Adjusted OR (95\% CI) \\
\hline \multicolumn{2}{|l|}{$\begin{array}{l}\text { Think doctor would } \\
\text { recommend HPV vaccine }\end{array}$} \\
\hline No & ref. \\
\hline Do not know & $3.15(1.47-6.76)^{*}$ \\
\hline Yes & $12.87(4.63-35.79)^{*}$ \\
\hline \multicolumn{2}{|l|}{ Hepatitis B vaccination history } \\
\hline No doses received/do not know & ref. \\
\hline At least 1 dose received & $1.37(0.70-2.69)$ \\
\hline \multicolumn{2}{|l|}{ No. Lifetime sexual partners } \\
\hline$<5$ & ref. \\
\hline 25 & $3.39(1.34-8.55)^{*}$ \\
\hline Concern about getting HPV-related disease & $0.96(0.48-1.90)$ \\
\hline Perceived severity of HPV-related disease & $1.92(1.18-3.14)^{*}$ \\
\hline Perceived likelihood of getting HPV-related disease & $1.84(0.92-3.70)$ \\
\hline Perceived effectiveness of HPV vaccine & $1.97(1.27-3.06)^{*}$ \\
\hline Anticipated regret if chose not to get vaccinated and later developed HPV infection & $2.39(1.57-3.61)^{*}$ \\
\hline
\end{tabular}

Multivariate model consisted of all variables included in table.

HPV indicates human papillomavirus; OR, odds ratio; CI, confidence interval; ref., referent group.

* $P<0.01$. 